\title{
Accidental sodium chloride poisoning in sheep - a case study
}

\author{
Zuzana Široká1, Vlastimil Labaj², Martin Pijáček ${ }^{3}, Z_{\text {deňka Svobodová }}^{1}$ \\ ${ }^{1}$ University of Veterinary and Pharmaceutical Sciences Brno, Faculty of Veterinary Hygiene and Ecology, \\ Department of Animal Protection, Welfare and Behaviour, Brno, Czech Republic \\ ${ }^{2}$ Regional Veterinary Administration of the State Veterinary Administration for Moravian-Silesian Region, \\ Ostrava - Vítkovice, Czech Republic \\ ${ }^{3}$ State Veterinary Institute, Olomouc, Czech Republic
}

Received February 28, 2017

Accepted October 2, 2017

\begin{abstract}
In April 2015, a farmer in the Silesia Region, Czech Republic, suffered a massive loss of 51 sheep. Two days before the incident, the flock of approximately 300 sheep were transferred from their wintering stable to pastureland. The pasture had a brook as a source of drinking water and in addition, a water cistern with drinking water was provided as well as mineral salt licks; otherwise the animals were left to graze with no supplementary feed. During the night of 28/29 April it rained heavily. The salt blocks were damaged and softened, showing signs of intensive nibbling. In the morning of 29 April, dead animals were found all over the pastureland. Four of the sheep were sent for post mortem examination and toxicological analyses. Evidence of extremely high concentrations of $\mathrm{NaCl}$ in the liver samples and characteristic pathologicalanatomical findings confirmed the suspicion that the sheep had died of fodder salt poisoning. The rapid and extreme change in the weather conditions, soaking of the otherwise solid salt lick, and the short period of acclimatisation of the sheep to the pasture were at fault. The main preventative measure is to respect the transitory period for the animals to get accustomed to a different kind of roughage and local conditions. This case is noteworthy because of the number of animals affected, the speed of the poisoning progress, and the detailed pathological examination of the dead animals. As there is a limited number of articles describing salt poisoning in sheep, this case study may contribute to the broadening of the knowledge on this issue.
\end{abstract}

Intoxication, mass death, salt lick, short acclimatisation

\section{Case description}

History

On 29 April, 2015 the Regional Veterinary Administration (RVA) was notified that at one farm in the Silesia Region, Czech Republic, several dozens of sheep had died and authorities were asked to investigate this incident. The employee of the farm informed the RVA inspector that the dead animals were found all over the enclosure. She also reported that on instruction of the managing director of the farm, 4 of the dead sheep were immediately transported for examinations of the cause of death to the State Veterinary Institute (SVI).

During on-site investigations, the RVA inspector discovered that on Monday, 27 April the farmer had transferred the flock of 295 head of sheep (ewes, ewe hoggs, and lambs) from their winter housing in a building to one of the enclosures for summer grazing. The sheep died in the night from 28 to 29 April and during the morning of 29 April. A total of 51 sheep of all categories died (ewes, ewe hoggs, lambs). The inspector arrived on site when all the live animals had been moved to the neighbouring enclosure and all the cadavers had been transported from the pasture to the farmer's barn to prevent access of predators or other animals or persons. 
Clinical symptoms, examination of the site of the poisoning and inspection of the dead animals

Inspection of the live animals showed no clinical symptoms of disease. Their reactions and escape reflexes were very good, they were all feeding or resting quite undisturbed. By the next day, 30 April, no animal in the flock had died and no disease with visible clinical symptoms had developed. Feed and water intake were standard, the animals were calm and all their physiological reflexes were preserved. Thus, no conclusions could be made based on clinical symptoms.

The grass on the pastureland was about $20 \mathrm{~cm}$ tall and in no enclosure showed signs of unusual disturbance or non-standard appearance. The sheep were supplied with water from a mobile cistern. A small stream flows through the enclosure where the sheep died (it has its start in the enclosure) and the sheep also drank it. The enclosure of the pastureland where the sheep died was supplied with 4 lumps of $10 \mathrm{~kg}$ compressed salt licks; a sample of approximately $2 \mathrm{~kg}$ was taken from this salt lick and sent for examination to the SVI together with information about the product. On all four lumps of the salt lick, the signs of intensive nibbling were evident (Plate I, Fig. 1). The farmer informed the authorities that on 28 April, the weather had suddenly changed and the temperature had dropped (during the night to around $0{ }^{\circ} \mathrm{C}$ ) and it had rained heavily for several hours.

Examination of the bodies of the animal cadavers ( 5 ewes checked by an RVA inspector) showed no visible signs of external injury. Death was not accompanied with diarrhoea and no oedemas were discovered affecting mucous membranes of the head or genitals. There was no discharge from body orifices and no haemorrhages on the visible mucous membranes or skin. The only visible and marked symptom was severe cyanosis of the visible mucous membranes. After examination of the cadavers and findings of salt licks on the pastureland, suspicion of $\mathrm{NaCl}$ poisoning was pronounced. No other source of death was considered at that time.

\section{Subsequent procedure}

The RVA instructed the farmer to take preliminary measures, effective immediately, in terms of isolation of the animals, ban on their transfer with the exception of transfer of cadavers to the rendering plant, and preparation of lists of animals (living, dead, sent to the SVI). It was the farmer's duty to monitor the health condition of the animals and to notify the RVA of any changes immediately.

\section{Pathological-morphological examination \\ Cadavers of 4 sheep were examined in the SVI.}

The first ewe weighed $39 \mathrm{~kg}$, was shorn and her nutrition status was poor. The body surface bore no visible signs of injury, no ectoparasites were discovered. Discharge of the content of the fore stomach from the nostrils and mouth was observed. The skin on the lips, interdigital space, on the udder and anogenital region showed no visible pathological changes. The conjunctiva and visible mucous membranes were anaemic. The mucous membrane of the gingiva around the incisors and on the pulvinus dentalis were markedly pinkish in colour, but no ulceration or any other pathological changes were found. No changes were seen on the mucous membrane of the soft and hard palate and tongue. No changes were observed on the other natural body orifices. The udder was in lactation and again showed no visible changes. Another finding was oedematous effusion of the hypodermis on the right pelvic limb in the region of the knee joint and on the ventral side of the neck. On the mucous membrane of the trachea a pinkish foamy fluid was observed, and suffusion of part of the thoracic cavity with a bloody exudate. The pleura and visceral pleura showed no changes, the lungs were aerial and not imploded, the oedematous body was soaked with abundant discharge of a bloody foamy fluid on the section. The 
thickening and oedematous soaking of the pericardium were marked. In the pericardium cavity a clear yellowish exudate was observed. There were no effusions or blood shedding in the abdominal cavity. There were no changes on the organs of the abdominal cavity. However, enlargement and effusion of mesenteric lymph nodes were discovered. The fore stomachs were filled with food of mushy consistence, rich green in colour, without any atypical odour, with no admixture of grains or presence of foreign bodies. The mucous membrane was intact, no changes were observed. The abomasum was flatulent, partly filled with a green watery content, the mucous membrane of the abomasum was intact, and no changes were evident. The small intestine with parts of an oedematous wall (Plate I, Fig. 2), the erythematous mucous membrane with no signs of ulceration (Plate I, Fig. 3), and the digesta of a thin mushy consistence and whitish colour had no blood admixture. The content of the appendix was dark green and mushy, the mucous membrane was slightly erythematous. The content of the caudal parts of the intestines was pasty and dark green, the content of the large intestine and rectum was thickened and dark green. The mucous membrane of these alimentary parts showed no visible inflammatory changes. There were no macroscopic changes on the skeletal muscles but the muscle fascia of the deeper muscle groups, namely on the pelvic limbs, were markedly oedematous and soaked (thickened up to a gelatinous consistence) (Plate I, Fig. 4). Meninges were congested, the cerebral tissue showed no macroscopic changes.

In the second ewe, weighing $47 \mathrm{~kg}$, similar changes were found; moreover, petechiae and erythema of the mucous membrane of the urinary bladder was detected (Plate I, Fig. 5). In the third cadaver of a ewe hogg weighing $27 \mathrm{~kg}$, the hair in the anogenital region and on the tail was caked with excrements. In contrast to the previous sheep, the muscle fascia and skeletal muscles showed no signs of soaking and of other pathological changes. The fourth cadaver was a lamb weighing $17 \mathrm{~kg}$ which showed the same injuries as ewe No. 1, including the soaking of muscle fascia.

In acute cases of salt poisoning, the pathological changes are frequently non-specific and are seldom conclusive (except for swine). But the irritation and hyperaemia of the digestive tract, anasarca of the skeletal muscle, and hydropericardium found in our case can be considered as typical findings supporting the diagnosis of salt poisoning.

\section{Laboratory examinations}

The laboratory examination was performed on fresh liver tissue obtained during the autopsy using titration method, and suggested sodium chloride poisoning. Chemical and toxicological examinations of the liver of the sheep discovered that the concentrations of $\mathrm{NaCl}$ ranged between 4620 and $4970 \mathrm{mg} / \mathrm{kg}$, while concentrations higher than $3000-3500 \mathrm{mg}$ of $\mathrm{NaCl}$ in fresh liver tissue are considered as evidence of poisoning.

In one case (ewe No. 2) bacteriological cultivation examination of the organs detected Pasteurella multocida and Streptococcus equinus. Coprology examinations resulted in only sporadic findings of eggs of gastrointestinal nematodes, tapeworms, and coccidia oocysts.

\section{NaCl poisoning}

Sodium chloride poisoning may be caused by excessive intake of salt (direct salt poisoning) or by a shortage of water (indirect salt poisoning); more often than not by a combination of these two factors (Kahn 2010; Gupta 2012). The concentration of sodium chloride in the feed or drinking water which meets the physiological demands of the organism without causing toxicity is less than $0.5 \%$. Salt is more toxic if dissolved or mushy, i.e. readily accessible to absorption, than if solid, e.g. in salt lick blocks (Kahn 2010). Salt poisoning appears most frequently in pigs and poultry and is less frequent in cattle and horses; it has also been detected in sheep (Sandals 1978; Radostits 
et al. 2006; Duarte et al. 2014). Herbivorous animals tolerate higher doses of salt because, naturally, their feed ration contains less sodium. In omnivorous animals the $\mathrm{Na}: \mathrm{K}$ ratio in feed is approximately $1: 1$; in herbivorous it is $1: 10$. Sheep probably belong to the less susceptible species and their lethal dose (LD) is approximately $6 \mathrm{~g}$ of NaCl$/ \mathrm{kg}$ of body weight (Buronfosse 2000; Kahn 2010). Lactating animals are more susceptible to salt poisoning because of the loss of water in the milk they produce. Young animals are more susceptible to poisoning because they have a low concentration of plasma proteins, and poultry because they have no taste buds in the beak cavity and also because their kidneys have a lower concentration ability (Svobodova et al. 2008).

The mechanism of the effect is ion and osmotic imbalance. Sodium and chloride ions are responsible for the osmotic balance in the body. They are almost completely absorbed in the digestive tract and are distributed into the whole body. Increased blood osmolality causes thirstiness, stimulates water uptake and because it affects the antidiuretic hormone, it causes water retention in the organism. This compensation mechanism decreases osmolality and is effective only if the animal has enough water at its disposal. If the compensation mechanisms fail, sodium begins to draw water out of the cells (intracellular dehydration) into the extracellular space and causes swelling. It also crosses the bloodbrain barrier and in the process, if it is acute, dehydration of neurons and swelling in the intercellular matter take place in the brain, as well as changes in blood circulation of the brain and haemorrhages. In severe cases we can observe neurological symptoms (Gupta 2012).

Clinical symptoms of poisoning develop within 1-2 days. If the poisoning is caused by water deprivation (indirect poisoning), the symptoms may appear as late as after 4-7 days (Gupta 2012). Intake of a higher amount of salt will cause irritation of the mucous membrane of the gastrointestinal tract. If the irritation is not severe, the symptoms of the poisoning will appear only as loss of appetite, vomiting, and diarrhoea. Rapid intake of very high doses of salt will cause serious gastroenteritis, disorder of the electrolyte balance, and dehydration of more than $10 \%$, and may result in acute death. When the intake of salt is slower, the concentration of sodium in the blood and in the intercellular region gradually increases and other symptoms develop. In pigs nervous symptoms appear, such as compulsive walking, head pressing, and circling. The pigs adopt a "doggy sitting position", suffer from head tremors and even fall on their side. In the terminal stage, the animals lie on their side, they "paddle" with their extremities and manifest signs of opisthotonus. Acute salt poisoning in cattle appears as gastroenteritis, salivation, thirst, dehydration, weakness, ataxia, and convulsions. In some cases it may result in blindness or aggressive behaviour of the animal. The terminal stage in cattle is the same as in pigs (Pearson and Kallfelz 1982; Van Leeuwen 1999; Senturk and Huseyin 2004; Kahn 2010). Opisthotonus and convulsions have been described in goats (Buronfosse 2000), while somnolence, decreased reflexes, mydriasis, nystagmus, tachycardia, intense thirst, tympany, opisthotonus and generalized muscle fasciculations have been reported in sheep (Scarratt et al. 1985; Duarte et al. 2014).

Pathological-morphological findings involve distinct changes in the gastrointestinal tract. The stomach shows various stages of damage, from irritation and inflammation to marked ulcerations and haemorrhages. The content of the gastrointestinal tract may be liquid, or in the case of indirect poisoning, abnormally dry. The intestinal mucosa is hyperaemic, and necrotic changes may occur. Histopathological lesions in the brain include cerebral oedema and meningitis (Trueman and Clague 1978; Scarratt et al. 1985; Modra et al. 2009). Other signs that may be evident are anasarca of the skeletal muscle; in cattle and poultry hydropericardium; in poultry also ascites, pulmonary oedema, and nephrosis (Svobodova et al. 2008). In acute cases, the pathological changes are frequently non-specific (Kahn 2010). 
Laboratory diagnosis is based on evidence of sodium ions or total $\mathrm{NaCl}$. Sodium chloride poisoning is conclusive if post mortem examination discovers sodium concentrations of more than $2000 \mathrm{mg} / \mathrm{kg}$ in the brain (found in cattle and pigs) (Kahn 2010). Conclusive is also the content of $\mathrm{NaCl}$ in the liver, which is higher than $3000 \mathrm{mg} / \mathrm{kg}$ in case of poisoning. In a living animal, salt poisoning may be diagnosed if the concentration of sodium in the serum or plasma is high (hypernatraemia) (Svobodova et al. 2008).

Therapy is based on controlled hydration. In the case of salt poisoning the water uptake must be limited and gradual so as not to cause or intensify brain oedema. Hypernatraemia should be treated preferably within 48 to $72 \mathrm{~h}$. If it is not possible to monitor the sodium level in the serum/plasma, the water uptake should be restricted to $0.5 \%$ of live weight at 60-min intervals (orally or with a stomach probe) (Svobodova et al. 2008). For small animals intravenous fluid therapy is recommended together with correction of hypernatraemia. Yet, even when therapy is timely, the mortality may exceed $50 \%$ (Kahn 2010).

\section{Conclusion of the case}

The cause of death in the investigated flock of sheep was specified as fodder salt poisoning. No other common factor was found that could have caused the death of the animals. The source was compressed natural rock salt containing only $\mathrm{NaCl}$. Four lumps of this lick were found on the pasture and the sheep had ingested the lick intensively. The sheep were poisoned even though according to the information of the farmer, the animals of this flock had full access to the same salt lick during the whole winter. At the time of this emergency they had access to water from the water cistern and a natural source of water in the small stream.

The follow-up check on 7 May revealed that the animals had been transferred back to the run for winter housing and that they showed no symptoms of disease. From the time of the investigation of the poisoning until the follow-up check only two lambs died, and only because their mothers had died of poisoning and artificial rearing of the young had failed.

Considering that the cause of death of the sheep had been explained and no outside cause was proved, the preliminary measures were cancelled. The farmer was instructed on the risk of $\mathrm{NaCl}$ poisoning in connection with the first spring grazing, and about preventative measures necessary to avoid such situations, especially about the need to provide the animals with a transitory period with the same feed they were fed during the winter, i.e. hay, as it is necessary to respect the transitory period for the animals to get accustomed to a different kind of roughage, and particularly, to provide a sufficient amount of water and number of watering places for supplying such a numerous flock with water.

The case was closed as a sum of unfortunate circumstances which the farmer could not have predicted. The fault lied with the rapid and extreme change in climate conditions, soaking of the otherwise solid salt lick, and the short period of acclimatization of the sheep to the pastureland. The combined events of handling, separation for the time of transport and regrouping were stressful for them. The sudden change of feeding and climatic conditions described in this case points out the necessity to thoroughly accommodate the animals and ensure their welfare requirements.

\section{References}

Buronfosse F 2000: Intoxication by sodium chloride in a herd of goats. Summa 17: 75-76

Duarte MD, Bezerra Jr. PS, Lima DHS, Barbosa JD 2014: Salt poisoning outbreak in sheep in the state of Para. Pesquisa Vet Brasil 34: 1061-1068

Gupta RD (Ed.) 2012: Veterinary Toxicology. Second Edition, Academic Press, London, 1438 p.

Kahn CM (Ed.) 2010: The Merck Veterinary Manual. Tenth Edition, Merck \& Co., Inc., Whitehouse Station, pp 2624-2626 
Modra H, Svobodova Z, Siroka Z, Dobsikova R, Mikula P 2009: Special Veterinary Toxicology (In Czech). University of Veterinary and Pharmaceutical Sciences Brno, Brno, 165 p.

Pearson EG, Kallfelz FA 1982: A case of presumptive salt poisoning (water deprivation) in veal calves. The Cornell Vet 72: 142-149

Radostits OM, Gay CC, Hinchcliff KW, Constable PD 2007: Veterinary Medicine: A textbook of the diseases of cattle, horses, sheep, pigs and goats. Tenth Edition, Saunders Ltd., Philadelphia, 2065 p.

Sandals WCD 1978: Acute salt poisoning in cattle. Can Vet J 19: 136-137

Scarratt WK, Collins TJ, Sponenberg DP 1985: Water deprivation-sodium chloride intoxication in a group of feeder lambs. J Am Vet Med Assoc 186: 977-978

Senturk S, Huseyin C 2004: Salt poisoning in beef cattle. Vet Hum Toxicol 46: 26-27

Svobodova Z (Ed.) 2008: Veterinary Toxicology in Clinical Practice (In Czech). ProfiPress, Prague, 253 p.

Trueman KF, Clague DC 1978: Sodium chloride poisoning in cattle. Austr Vet J 54: 89-91

Van Leeuwen JA 1999: Salt poisoning in beef cattle on coastal pasture on Prince Edward Island. Can Vet J 40: 347-348 
Plate I

Široká et al.: Accidental sodium ... pp. 213-218

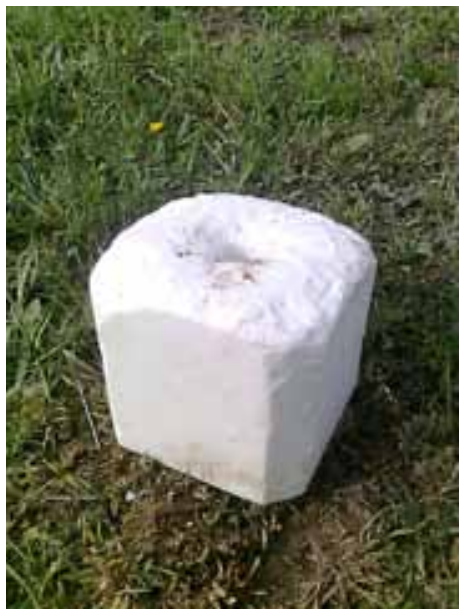

Fig. 1. Nibbled salt lick

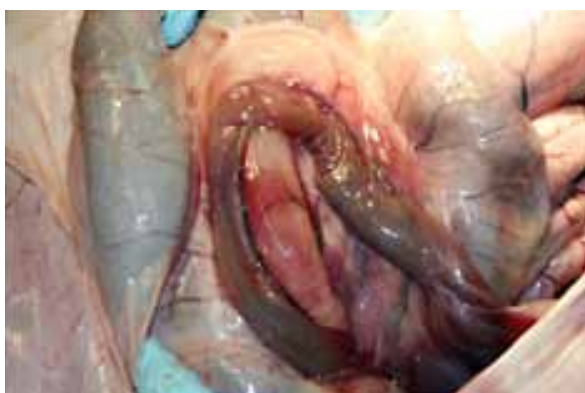

Fig. 2. Small intestine with oedematous wall

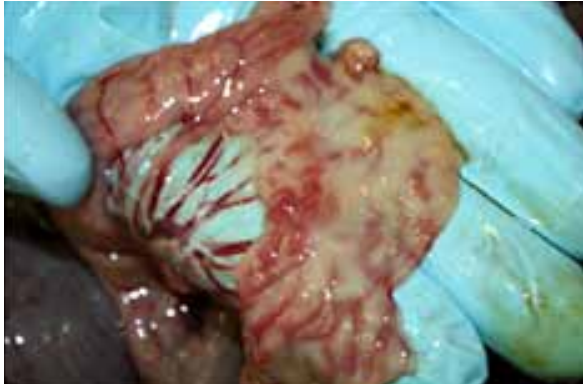

Fig. 3. Swelling and erythema of the mucous membrane of the small intestine

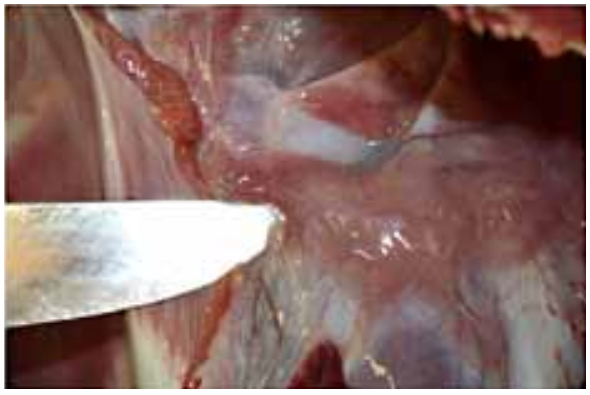

Fig. 4. Oedematous changes of muscle fascia of the pelvic limbs

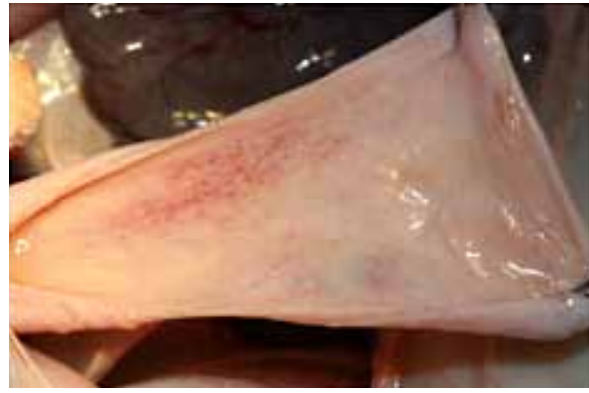

Fig. 5. Petechiae on the mucous membrane of the urinary bladder 